\title{
CASELOAD MIDWIFERY IN A MULTI-ETHNIC COMMUNITY: THE WOMEN'S EXPERIENCES
}

\section{AUTHORS}

Sarah Beake, Kings College London

Luisa Acosta, University Of West London

Pauline Cooke, Imperial College Healthcare NHS Trust

Christine Mccourt, City University London

\section{Abstract}

Objective: To evaluate caseload midwifery in a relatively deprived and ethnically diverse inner-city area.

Design and setting: Semi-structured interviews were undertaken with 24 women from diverse ethnic backgrounds, 12 of whom had received caseload care and 12 women from an adjacent area who had received conventional maternity care in a large inner-city maternity unit. Framework analysis was adopted drawing on links with the authors' previous work on women's views of caseload midwifery.

Findings: Key themes from previous work fitted well with the themes that emerged from this study. Themes included 'knowing and being known', 'person-centred care', 'social support', 'gaining trust and confidence', 'quality and sensitivity of care' and 'communication'.

Key conclusions and implications: Women from this socially and ethnically diverse group of women had similar views and wanted similar care to those in previous studies of caseload midwifery. Many of the women receiving caseload care highlighted the close relationship they had with the midwives and as a result of this 
felt more able to discuss their concerns with them. This has the potential not only for improved quality of care but also improved safety.

Key Words: caseload midwifery, continuity, maternity, ethnicity. 


\section{CASELOAD MIDWIFERY IN A MULTI-ETHNIC COMMUNITY: THE WOMEN'S EXPERIENCES}

\section{Introduction}

Individual caseload midwifery is an approach to care that offers an increase in continuity for women who are cared for by a known midwife throughout pregnancy, birth and the postnatal period. Caseload midwives generally carry a personal caseload of women with both high and low risk pregnancies, working across hospital and community service boundaries. They provide midwife-led care for women at low risk on their caseload and collaborate with maternity team members in co-ordinating and providing care for women at higher levels of clinical risk. They attend births in women's homes, midwife-led or obstetric units, depending on the woman's choice and eligibility. In most services they work in partnerships and group practices to provide cover for their caseloads, for mutual support and peer review of care.

Caseload schemes have been introduced particularly in the UK and Australia, as part of an integrated maternity system, while in countries such as Canada, most midwife care conforms to the caseload model, but midwives do not yet form a fully integrated part of the public health care system. Research to date indicates that caseload midwifery increases women's satisfaction when compared with traditional midwifery practice (Homer et al. 2002, McCourt et al. 1998, McCourt \& Stevens 2006, Williams et al. 2010) but there has been limited research on the implementation of this form of practice serving deprived multi-ethnic communities.

In the UK caseload midwifery has been in existence in the National Health Service for nearly 20 years, having been first introduced to implement the Department of Health recommendations that women should be offered continuity of care throughout pregnancy, childbirth and the postnatal period (Department of Health 1993). 
Continuity of care in maternity has continued to be a recommendation made by the Department of Health at the same time emphasising the needs of vulnerable and disadvantaged women (Department of Health 2004, 2007). Greater continuity has also been advocated in health care more widely as a contribution to safety and quality of care (Nutting et al. 2003). An English national survey of women's experience of maternity care (National Perinatal Epidemiology Unit 2007) found that women from ethnic minorities and those living in the most deprived areas were less likely to have felt they were treated with respect and talked to in a way they could understand. One of the key areas of concern in the Healthcare Commission's review of maternity services (2008) was that there was not adequate continuity of care for women. Caseload midwifery has been introduced in a number of units in the UK and in other countries with integrated midwifery services with favourable results, including increased continuity, a reduction in intervention in labour and increased satisfaction for women (Beake et al. 2001, Benjamin et al. 2001, Homer et al. 2001, Homer et al. 2002, McCourt et al. 1998, McCourt et al. 2006, North Staffordshire 2000, Page et al. 2001, Sandall et al. 2001). These findings echo those of wider studies of continuity in health care (Haggerty et al. 2003, Nutting et al. 2003) Despite positive findings, the introduction of caseload practice has not been widespread, although there is little research to suggest why this may be. Although a Cochrane Review of midwife led care indicates this form of midwife-led care is clinically and cost-effective (Hatem et al. 2008) it is widely anecdotally perceived as an un-necessary and unsustainable luxury. As there is now more emphasis in UK policy on meeting the needs of vulnerable and disadvantaged women, some maternity units in the UK have chosen to focus on offering this form of care to the more disadvantaged women in their catchment area, sometimes in association with Sure Start schemes or Children's Centres (Finlay and Sandall 2009). 
There is considerable wider evidence of inequity of access to health care and for maternity care specifically, with indications that this is a matter of safety as well as quality. This evidence underpins the view that women's experience of care is deeply connected to both quality and safety, rather than simply being a nicety. Epidemiological evidence indicates interaction between indicators of social deprivation and minority ethnicity: put simply, women in minority groups are also more likely to be poor and specific groups such as recent migrants may lack social support (Barnard \& Turner 2011). Minority ethnicity, living in a socially deprived area and being born outside the UK are all associated with booking late for maternity care (Redshaw \& Heikkila 2010) and lack of attendance for care is associated with poorer clinical outcomes (Kurinczuk et al. 2009) highlighting the importance of developing models of care that increase access and responsiveness of care. The UK CMACE Report in 2011 highlighted late booking and poor attendance for antenatal care as associated with maternal deaths and recommended measures to increase take up. Similarly, it highlighted the higher rates of deaths and 'near misses' among minority ethnic women and those who are socially deprived, with such women also being more likely to be poor attenders for care (CMACE 2011). This indicates a need to address barriers to care for some women. The report also indicated areas where care that is accessed is sub-optimal, and successive maternity safety enquiries have implicated difficulties in accessing care, poor responses from professionals, lack of co-ordinated care and poor communication between professionals as well as between the women and professionals (De Souza \& Garcia 2004). National surveys indicate that women living in more disadvantaged area and those from minority ethnic groups are offered fewer choices and are less satisfied with care (Redshaw et al. 2006) and that women who experienced continuity of care antenatally were more likely to feel they were given choices, information and kind, respectful care (HCC 2007). Despite this growing evidence, few studies so far have focused on the views and needs of minority ethnic women, (McCourt and Pearce 2000, Harper-Bulman 
and McCourt 2002, McLeish 2005, McAree et al. 2010) or on how maternity services may best be designed to meet their needs more effectively. McLeish's study, focused on asylum seekers' experiences, highlighted lack of access and information, isolation and unmet needs for social support, as well as explicit barriers such as hostility and racism, while studies of midwives' attitudes indicate that the way in which care is organised may encourage stereotyping of their clients (Green et al. 1990).

This study was designed to evaluate the outcomes of caseload midwifery practice in a socially deprived and ethnically diverse inner-city area. The caseload practices that formed the focus of this study were introduced into this inner-city hospital service approximately a year before the study commenced. There were two group practices of 4-6 midwives, each linked to one or more GP practices in a socially deprived neighbourhood, as a specific targeted policy. The midwives had, for the most part, previously worked in conventional community midwifery teams, serving these neighbourhoods, although a few relocated from hospital based practice within this maternity service. In either case, these midwives would not have previously practised midwife-led care for low-risk women, or with a defined caseload following women through from pregnancy to birth and postnatal care. This article describes one aspect of the study, the women's views of the care they received. Other aspects of the study including the midwives' experiences of working in a caseload group practice will be reported elsewhere. However, we refer to midwife experiences in our discussion of the key themes, since there was a high level of concordance between the women's perspectives and those of the midwives regarding the care relationship, suggesting relational continuity and reciprocity is an important aspect of this model of care and its sustainability (Hunter 2006, McCourt \& Stevens 2009).

\section{Methods}


Individual, semi-structured interviews between three to six months postnatally were conducted at a time and venue of the woman's own choice, for the most part this was the woman's home. Interviews were chosen as the most appropriate way of gaining insight into the women's views and experiences in this context as it avoids the common problem of skews in questionnaire survey response rates towards white middle class women. It also enables more detailed exploration of what matters to the women.

\section{Sample}

Two samples of 12 women (caseload and standard care) were interviewed to ensure a sufficient sample for saturation of data was reached. These were drawn from a list of all women who gave birth within the local community area in a two-month period. Invitation letters were sent to all women on the list who had received caseload care and all those who agreed to participate were interviewed until no new themes emerged from analysis. A sample of 12 women from adjacent postcode areas receiving conventional maternity care were also interviewed to enable exploration and understanding of women's usual maternity experience within this setting. Women from the list who matched those interviewed in terms of parity and ethnicity as far as possible were contacted and invited to participate until a comparable sample was achieved. Women who had experienced a stillbirth or neonatal death were excluded since they might be distressed by contact with a researcher asking about their maternity experience. Although we planned to use bilingual interviewers or interpreters as needed, no women who did not speak English consented to participate.

\section{Analysis}

A narrative approach was taken in the interview, encouraging the woman to tell the story of their maternity experience. The interviews were taped with permission and 
then transcribed. Grounded theory principles were used to guide the overall approach and data analysis (Strauss and Corbin 1990). Open coding was used, followed by coding to identify themes emerging from the data. Transcripts were analysed independently by different members of the research team, who met several times to discuss results, explore the themes and organise these into categories. However, during analysis it was noted that links could be drawn with previous work on women's views of caseload midwifery (McCourt and Stevens 2009) and framework analysis was therefore adopted (Ritchie et al. 2003). A framework for analysis drawing on our previous work was drawn up and the data were then analysed in relation to this, while still allowing it to be examined for new or dissonant emergent themes. The five key stages typically applied in framework analysis were followed: initial familiarisation with the data by immersion in reading the transcripts in order identify recurrent themes and concepts; identifying a thematic framework identifying all the key issues, concepts and themes drawing on prior issues; indexing all the data; forming charts for each theme, the charts contain distilled summary of views and experiences rather than verbatim quotations; mapping and interpretation. (Pope et al. 2009).

Ethical permission for the study was sought and obtained from the National Research Ethics Committee (ref; 07/H0710/55).

\section{Findings}

Socio-demographic details of the interview participants are summarised in table 1. The women were from very diverse ethnic backgrounds: 8/12 women in the caseload care group and 10/12 in the usual care group were of minority ethnic background, defined as not white British or European. 
The relevant neighbourhoods for the caseload care groups were measured as being among the top $10 \%$ of areas of social deprivation in England according to their Index of Multiple Deprivation score.

The key themes identified in our analysis are shown in table 2, alongside the key themes identified in our earlier study, which formed the framework for analysis. As indicated above, we found that the themes emerging from this current study fitted well with our earlier work on women's views of caseload midwifery, and our choice to use framework analysis arose from this finding in the preliminary analytic work.

\section{Knowing and being known}

Knowing the midwife was a theme that emerged as being important to women in both the caseload group and those who received standard care. The women who received caseload midwifery appreciated knowing the midwife who cared for them while those receiving standard care, who for the most part did not know the midwives caring for them, spoke of the possible benefits there would be had they known them.

\section{Like a friend or kin}

As with the previous study (McCourt and Stevens 2009) 'knowing the midwife' was more than having met someone once or twice before, it was building up a relationship that was likened to that of a friend or kin:

But she was like, I never think she was midwife, I was thinking, believe me, I was so close to her like a sister, even closer than a sister. (CW1) 
But I feel she was like a mum. Believe me, believe me, it's like a mum. When I had my baby she was like this, you know, she kiss me and she was very kind. (CW 5)

But it's different because I had a relationship with them. $V$ was a great friend... (CW 6)

Although the relationships were likened to those with family there was a difference as described:

Sometimes they are more into it than the family. They are helpful and my family can sometimes give you trouble (CW 11)

However one woman described how she had had a difficult time in labour; there had been problems inserting the epidural and the midwife was unhappy with the management. She suggested that perhaps the midwife was too involved with her. Midwives' responses (which will be reported separately) indicated that such relationships were a great source of professional satisfaction, but also demonstrated awareness of the need to develop appropriate boundaries in managing such a role.

Feeling safe and relaxed

As with a friend or member of the family the women felt safe and relaxed with the caseload midwives:

You know when you get to know someone, it's easier to talk to them and stuff. (CW 4) 
And in hospital I don't know many people you would go through, how many people would be at the birth.... I was comfortable with her, she was comfortable with me and I think that's the crucial thing in a birth - that you have to be comfortable. (CW 12)

\section{Being able to confide}

With someone they knew the women felt much more able to confide. With vulnerable women this would be particularly important. It was illustrated in the first study (McCourt and Stevens 2009) as to how difficult one woman found it to describe the domestic violence she was suffering. In this study the women felt able to talk about issues they would not discuss with anyone else:

So I used to get along with her so good. I used to talk to her about everything that I didn't even speak to my husband or mum about ....... You know when you get to know someone, it's easier to talk and stuff (CW 4)

I spoke to her about my family problem, about my problem. She just made me feel like I was welcome to her heart, it's like her heart just opened the doors for me (CW 8)

\section{Repeating your history}

Being known by the midwife meant that the women did not have to repeat their history every time they met them, which they appreciated, while those under standard care were often frustrated by encounters with professionals who did not know them:

It's better to have one, because every time you meet the different one, you have to tell everything, the whole story. (CW10) 
There is no consistency there? They don't know the full story, whereas if you have one or two they sort of get to know you, they know your history, your medical history and everything else. Otherwise you have got to keep retelling the whole thing to everybody. (CW9)

The women receiving standard care raised the issue of having to repeat everything each time they met someone new:

And then you have to explain everything again, what you did with the other one and you don't feel the same. Because everything they do individually they are different, and I think we should stick to one, unless there's actually a big problem (SW3)

Because when she knows you and she doesn't need to ask you the same questions every time. (SW5)

It was only I think twice I had the same midwives, every time there was someone new which can sometimes be a bit unnerving ... sometimes it works well because if you don't like the midwife but other times you almost have to repeat everything again and again... it can be a bit disconcerting at times SW8)

As also found in our previous study, for some of the women the caseload midwife had cared for them in a previous pregnancy so knew personally what had happened then, which the women perceived as very helpful, and particularly for those with complicated obstetric histories: 
Yes she told us before if it happens to become pregnant again to call her if you want to. And when I found out, I did call her and she said it would be nice to be our midwife again. And it was nice to have her for both of them. We already knew her and it was nice. (CW 3)

Because with the first one, I was with $M$ and the second one, and I was happy with her, because she knew me. And it was all everything was perfect. (CW10)

Knowing the extended family

Working in a small geographical area the midwives were often known by other members of the family who lived in the area:

She's famous, yes she's famous because my sister-in-law told me she had a baby with $S$... Yes, so all the family know her! (CW 5)

This indicates that continuity of care may be more than a matter of relational continuity with individual women, but facilitates family and community-centred care.

\section{Person-centred care}

In our earlier study, person centred care was highlighted by the phrase 'having someone there for me'. Women in this study also mentioned how they appreciated having some-one there for them:

$V$ referred me to the doctors she said if there's a problem just give me a ring (CW1) 
Anything I had I just called her. Sometimes she was in labour [sic] you know. We usually send text messages because that was easier for her you know just in case she was with another woman or something. So I just sent her a text message and when she was free she would call me (CW 4)

and she would just sit on the carpet in the bedroom, with her notes here you know. It was wonderful, I mean it was brilliant because she was just there for me (CW 12)

The value of this continued postnatally, as illustrated by this woman who felt able to contact the midwife after one month postnatal:

I wasn't well at the time, so it was very good she came. Normally midwives come about 10 days only (CW 11)

while a woman who had standard care suggested it would be better if women had more personalised care:

if you pick up a phone you can talk to them directly sometimes rather than I would have to call the hospital and speak to them (SW 8)

The impersonality the women described for hospital-based care, and variation in the responses of the midwives they met meant that they sometimes felt the service was not really caring for them at all:

With the bad midwives you just felt like you were some thing, you weren't even a person, you were just a pregnant thing that walks in and they do their 
job and then go home. It didn't feel very one to one friendly, "how are you feeling?" (SW 9)

This lack of person-centred care that women often experienced in busy units with rushed staff also connected to a perceived lack of social support in much of standard care.

\section{Social support}

Social support can be defined as practical, informational and emotional (Dykes et al. 2003, McCourt 2009). Women valued the emotional side of the social support they received from the caseload midwives:

She was very supportive. Sometimes I was scared about something you know and she would talk to me and explain everything. (CW3)

The support of having $V$ and $A$ is just totally invaluable, and it helped me so much and I would look forward to those days when they came so much. Any little questions that I had or any anxieties or worries or just knowing that somebody's there, especially with me, with my depression and the fact that post-natal depression is not uncommon when you have had depression. (CW 6)

She even came after one month after the birth. She was really kind and helped me. One month later she still came and really support and help me. (CW 11) 
Several of the women receiving standard care who had been born outside Europe described the lack of social support in this country without their extended families around:

Because in Africa there's so much help. What I mean so much help is that you may have large families, where if you give birth straight away you have people around you. (SW3)

In my country you do have mummy, you have sister and brother, you have brother's wife, it's all in the same area. And in my country, when a woman gives birth for 10 days she's just relax. Not here. And here next day you have to go collect your children from school. (SW1)

Their accounts suggested a perceived lack of support, while women receiving caseload care felt they had support from midwives that might otherwise not be available to those who lacked such family and community support.

\section{Gaining trust and confidence}

The first study described how the organisation of caseload midwifery helped women develop confidence, particularly younger mothers and those from socially disadvantaged backgrounds. This was echoed in our current study, which was focused on a more socially and ethnically diverse group of women:

we did have long chats and things and you just gain experience and know more confidence in the stories that they tell you about other births (CW 9)

The women also had trust and confidence in the midwives caring for them: 
you get used to know that person and you trust her and all that (CW 3)

The first time I didn't have gas, I mean I had it there but I did not use it ... it was that smell I couldn't but with S you know because I trusted her you know, because I had had her for nearly eight months ... I used to know she was not wrong so I used to listen to her and get advice (CW 4)

I felt safe and confident that she knew exactly what she was doing (CW 6)

Women who had standard care described similar views, when asked towards the end of the interview if there would be any benefits of having the same midwife caring for them:

Because every day when you see the same midwife your confidence is growing up, not going to be strange, you can tell easy I think (SW 1)

Once you get used to someone you get comfortable, you start trusting them because being pregnant is a time you are emotionally ... it's a time you need a good midwife to be there, somebody you can trust, you know, somebody you can actually call a friend as well, so actually changing midwives sometimes is mind-wrecking (SW 3)

\section{Quality and sensitivity of care}

Care in both the original and the current study was seen as more individualised and flexible, while care in hospital was viewed as often impersonal and rushed: 
They were just brilliant. They were also, where they were so great was they were just so enthusiastic about anything that I wanted to do, like homeopathy and lots of alternative therapies. (CW 6)

She called me and she said I am L, I am your midwife, and she said do you like to come visiting at home or would you like to go to the hospital for appointments? (CW7)

I think I am lucky. ...... it makes such a difference if they can just come to your home and see you at home you know in your own environment. .... I think it's more personal. (CW 9)

One of the women having standard care described how she felt in labour with different midwives coming and going:

This is different ones and that's horrible. You get used to one face and then another face comes in and it's like 'Oh please no' ... It is not good seeing different faces and different hands touching you all the time ... you feel a piece of meat. (SW 3)

and another expressed concern about the busyness of midwives leading to this:

I got the impression that they were looking after maybe 3 ladies at the same time (SW 10)

Many of the women were not happy with the antenatal clinics for similar reasons: 
That antenatal clinic it just felt you were a flock of sheep and you were just you know do this, do that, and put in line and obviously they know what they are doing but I don't know what's going to happen so and I didn't know when they do a sweep I didn't know what that was. (SW 9)

The hospital postnatal care for both groups of women came under particular criticism, although many of the women acknowledged the postnatal wards appeared short of staff. However the women having caseload care were visited by 'their' midwife and so did not feel quite so abandoned. One woman described how she felt with the caseload midwife visiting her on the postnatal ward:

she made me feel really special, honestly the way she treated me (CW 8)

and then concerning the staff on the postnatal ward commented:

only a few of them were nice. I think there should be more midwives, helpful ones (CW8)

The feeling of many of the women having standard care was that care on hospital postnatal wards was generally reasonable during the day, although variable and with busy staff, but poor at night:

All fine until night-time came and then and this is the universal cry I hear among ladies who've had babies at ... the absolute focus is in getting out before the night-shift come on. (SW 4)

\section{Communication}


This key theme emerged across all the themes, which came together to facilitate more effective communication between midwives and women. The themes which emerged, as reflected in the quotes included above, highlighted that since women felt they had a midwife they got to know, and who knew them, they described being more able to tell the midwife about their questions or worries, to confide in her, and to feel responded to. In this setting, continuity appeared to work on all three levels described in the wider literature on continuity - of informational, management and relational continuity, in such a way as to underpin good communication in maternity care (Haggerty et al. 2003) and to reduce potential barriers to care.

\section{Discussion}

This study explored women's experiences of caseload group practice midwifery in a socially and ethnically diverse catchment area of an Inner City teaching hospital with pockets of high levels of deprivation. Although this was a small, qualitative study, it captured the diversity of the local population, and interviews were conducted with a matched sample of women receiving standard care, to provide insight into the local service context. The respondents did not, however, include any women who did not speak English, so that the perspectives of the most recent migrants may not have been reflected. Such women are likely to have experienced greater barriers to care, and these may also be echoed in barriers to participating in research. Although we had planned interpreting for interviews as and when needed, difficulty was experienced in making contact with and gaining consent from non-English speaking women to participate. A different approach may have been needed to making contact and assuring them about the study in order to include them effectively. While a number of the respondents were not 'native' English speakers, all opted to be interviewed in English. 
We aimed to gain an understanding of whether this model of care was appropriate or even advantageous for such a community, since caseload midwifery has not been implemented on a large scale in the UK and in recent years, group practices have primarily been located in areas of social deprivation; for example, through links with Sure Start schemes. The midwives involved in these practices had been re-deployed within the relevant service from both community midwifery teams and hospital services, were given the opportunity to apply for this role and were formally interviewed for it. The midwives' response to working in this model, which will be described in detail in a separate article, indicated a high level of satisfaction and concordance with the views expressed by the women in this study, suggesting that the benefits of caseload care are reciprocated and iterative rather than simply a matter of benefit to women, potentially to the cost of the professional providing care (Finlay and Sandall 2009). Therefore, rather than seeing the care benefits described by the women as costly and unsustainable within a public health service, it may be hypothesised that the group practice caseload model of care studied here facilitates midwives' caring work and relationships.

Our initial analysis indicated that emerging themes were similar to those developed through a grounded theory approach in an earlier study of women's perceptions of caseload midwifery (McCourt and Stevens 2009). Therefore, we opted to use framework analysis, using the themes identified in our earlier study as the frame. This approach was not only effective, with little 'dissonant' data, but also helped us to identify that this very ethnically and socially diverse group of women held very similar perceptions and wishes for midwifery care to those reported in earlier studies. While the respondents were a diverse group in terms of their personal, social and cultural backgrounds, we were struck by the degree to which similarity rather than difference emerged in the analytical themes. We suggest that this reflects and rests on the core theme of person-centred care, which enables professional carer to progress from a 
concept of 'cultural competence' towards one of cultural safety. Relational continuity, combined with the ability to practice midwife-led care appeared to enable and encourage midwives to get to know the women and to respond to their needs in a way that is difficult in a busy, fragmented care system. While cultural competence has been advocated as a basic requirement to improve quality of care in health services, cultural sensitivity and cultural safety rest on relationships rather than attempts to learn about diversity in a fixed and theoretical way.

In addition, we hypothesise that the features of care highlighted by the women in this study may have safety as well as quality implications. A series of enquiry and quality reports have identified high rates of morbidity and mortality among women from minority ethnic groups, particularly those who are recent migrants and who do not speak fluent English, and among women who are socio-economically deprived or socially excluded (Lewis 2004, 2007, CEMACE 2011, Healthcare Commission 2005, Care Quality Commission 2011). Additionally, recent research on safety and quality of birth in different settings has highlighted the importance of women being able to speak up about their care and safety concerns and receive a response (Rowe et al. 2001, McCourt et al. 2011) and the impact of hierarchy and ability to speak up on quality and safety of care within obstetric units (Beck 2006, Lyndon et al. 2011, Mackintosh and Sandall 2010, Tanassi 2004). Similar issues have been raised for other areas of health care and studies have continued to identify barriers in patients feeling able to ask questions and communicate their concerns (Entwhistle et al. 2010, McCourt 2006, Pilnick and Dingwall 2011). Such barriers are particularly acute for migrant women and those who are more socially disadvantaged (Coulter and Ellis 2006, Kings Fund 2008, Raleigh et al. 2010). The findings of this study indicate that this model of care facilitates communication with maternity services through a relationship with a known midwife, for all women and particularly for those for whom problems of equity of access to care have been identified. They suggest that the 
model may help to overcome barriers to care and should be extended to comparable communities more widely.

\section{References}

Barnard, H., Turner, C., 2011. Poverty and ethnicity. A review of the evidence. York: Joseph Rowntree Foundation.

Beake, S., McCourt, C., Page, L., 2001. Report on the evaluation of one-to-one midwifery: second cohort study. London: Thames Valley University.

Beck, C.T., 2006. "Pentadic Cartography: Mapping Birth Trauma Narratives." Qual Health Res 16, 453-466.

Benjamin, Y., Walsh, D., Taub, N., 2001. A comparison of partnership caseload midwifery care with conventional team midwifery care; labour and birth outcomes, Midwifery 17 (3), 234-240.

Care Quality Commission, 2011. Investigation report. Barking, Havering and Redbridge University Hospitals NHS Trust: Queen's Hospital, King George's Hospital. October 2011.

http://www.cqc.org.uk/sites/default/files/media/documents/20111026 bhrut investigat ion report final.pdf

CMACE, 2011. Saving Mothers' Lives. Reviewing maternal deaths to make motherhood safer: 2006-2008. The Eighth Report of the Confidential Enquiries into Maternal Deaths in the United Kingdom. Centre for Maternal and Child Enquiries. British Journal of Obstetrics and Gynaecology 118, (Supplement 1),1-203.

Coulter, A., Ellis, J., 2006. Patient-focused interventions: a review of the evidence. London: Picker Institute/Health Foundation.

De Souza, L., Garcia, J., 2004. Improving services for disadvantaged childbearing women. Child: care, health and development, 30:599-611.

Department of Health, 1993. Changing Childbirth. Part 1: The Report of the Expert Maternity Group. London: HMSO.

Department of Health, 2004. National Service Framework for Children, Young People and Maternity Services. London: HMSO.

Department of Health, 2007. Maternity Matters: choice access and continuity of care in a safe service. London: HMSO.

Dykes, F. Moran, V.H. Burt, S. Edwards, J., 2003. Adolescent mothers and breastfeeding: Experiences and support needs - An exploratory study. Journal of Human Lactation 19(4), 391-401.

Entwistle, V.A., McCaughan, D., Watt, I.S., Birks, Y., Hall, J., Peat, M., Williams, B., Wright, J., for the PIPS (Patient Involvement in Patient Safety) group. 2010. 
"Speaking up about safety concerns: multi-setting qualitative study of patients' views and experiences." Quality and Safety in Health Care 19, e33.

Finlay, S., Sandall, J., 2009. "Someone's rooting for you": Continuity and Advocacy in Bureaucratic Maternal Health Care Systems, Social Science and Medicine, 69, 1228-1235. doi:10.1016/j.socscimed.2009.07.029

Haggerty, J.L., Reid, R.J., Freeman, G.K., Starfield, B.H., Adair, C.E., McKendry, R., 2003. Continuity of care: a multidisciplinary review. British Medical Journal 327(7425), 1219-1221.

Health Care Commission, 2005. Investigation into 10 maternal deaths at, or following delivery at, Northwick Park Hospital, North West London Hospitals NHS Trust, between April 2002 and April 2005. London: Healthcare Commission.

Healthcare Commission, 2008. Towards better births: a review of maternity services in England. London: Healthcare Commission.

Homer, C.S., Davis, G.K., Brodie P.M., Sheehan, A., Barclay, L.M., Wills, J., Chapman, M.G., 2001. Collaboration in maternity care: a randomized controlled trial comparing community-based continuity of care with standard hospital care. British Journal of Obstetrics and Gynaecology 108, 16-22.

Homer, C.S., Davis, G.K., Cooke, M., Barclay, L.M., 2002. Women's experiences of continuity of midwifery care in a randomised controlled trial in Australia. Midwifery 18(2),102-112.

Hunter, B., 2006. The importance of reciprocity in relationships between communitybased midwives and mothers. Midwifery 22, 308-322.

Kurinczuk, J.J,, Hollowell, J., Brocklehurst, P., Gray, G., 2009. Inequalities in infant mortality project briefing paper 1. Infant mortality: overview and context. In. Oxford: National Perinatal Epidemiology Unit.

[https://www.npeu.ox.ac.uk/files/downloads/infant-mortality/Infant-Mortality-

Briefing-Paper-1.pdf]

Lewis, G., 2004.Confidential Enquiry into Maternal And Child Health. Why

Mothers Die. The Sixth Report of the United Kingdom Enquiries into maternal deaths 2000-2002. London: RCOG.

Lewis, G., 2007. The Confidential Enquiry into Maternal And Child Health (CEMACH). Saving mothers' lives: the seventh report on confidential enquiries into maternal deaths in the United Kingdom. London: RCOG.

Lyndon, A., Sexton, J.B., Simpson, K.R., Rosenstein, A., Lee, K.A., Wachter, R.M., 2011 "Predictors of likelihood of speaking up about safety concerns in labour and delivery." BMJ Quality and Safety 10.1136/bmjqs.2010.050211.

Mackintosh, N., Sandall, J., 2010. Overcoming gendered and professional hierarchies in order to facilitate escalation of care in emergency situations: The role of standardized communication protocols. Social Science \& Medicine 71, 1683:1686.

McAree, T., McCourt, C., Beake, S., 2010. Perceptions of group practice midwifery from women living in an ethnically diverse setting. Evidence Based Midwifery 8(3), 91-97. 
McCourt, C., Page, L., 1996. Report on the evaluation of One-to-One Midwifery, London: Thames Valley University.

McCourt, C., Page, L., Hewison, J., Vail, A., 1998. Evaluation of one-to-one midwifery: women's responses to care. Birth 25(2), 73-80.

McCourt, C., Pearce, A., 2000. Does continuity of carer matter to women from minority ethnic groups? Midwifery 16(2), 145-154.

McCourt, C., 2006. "Supporting choice and control? Communication and interaction between midwives and women at the antenatal booking visit". Social Science \& Medicine 62,1307-1318.

McCourt, C., Stevens, T., Sandall, J., Brodie, P., 2006. Working with women: continuity of carer in practice. In: Page, L., and McCandlish, R., eds. The New Midwifery: Science and Sensitivity in Practice, 2nd edn. Oxford: Churchill Livingstone.

McCourt, C., Stevens, T., 2009. Relationship and reciprocity in caseload midwifery. In B. Hunter and R. Deery, eds. Emotions in midwifery and reproduction. Basingstoke: Palgrave Macmillan, pp17-23.

McCourt, C., 2009. Social support and childbirth. In: Squire C, (Ed.). The Social Context of Birth. Oxford: Radcliffe Medical Press, $2^{\text {nd }}$ edition,187-210.

McCourt, C., Rance, S., Rayment, J., Sandall, J., 2011. Birthplace qualitative organisational case studies: how maternity care systems may affect the provision of care in different birth settings Birthplace in England research programme. Final report part 6. NIHR Service Delivery and Organisation programme.

McLeish, J., 2005. Maternity experiences of asylum seekers in England. British Journal of Midwifery, 13(12), 782-785,

National Perinatal Epidemiology Unit, 2007. Recorded delivery: a national survey of women's experience of maternity care 2006. Oxford: NPEU.

North Staffordshire Changing Childbirth Research Team, 2000. A randomised study of midwifery caseload care and traditional 'shared-care'. Midwifery 16(4), 295-302.

Nutting, P., Goodwin, M.A., Flocke, S.A., Zyzanski, S.J., Stange, K.C., 2003, Continuity of primary care: to whom does it matter and when? Annals of Family Medicine 1, 149-155.

Page, L. Beake, S. Vail, A. McCourt, C. Hewison, J., 2001. Clinical outcomes of oneto-one midwifery practice. British Journal of Midwifery 9(11), 700-706.

Pilnick, A., Dingwall, R., 2011. On the remarkable persistence of asymmetry in doctor/patient interaction: A critical review, Social Science \& Medicine 72,1374-1382.

Pope, C., Ziebland, S., Mays, N., 2009. Qualitative research in health care, Analysing qualitative data. British Medical Journal 329,114-116.

Raleigh, V., Hussey, D., Seccombe, I., Halt, K., 2010. Ethnic and social inequalities in women's experience of maternity care in England: results of a national survey. Journal of the Royal Society of Medicine 103(5), 188-198. 
Redshaw, M., Rowe, R., Hockley, C., Brocklehurst, P., 2006. Recorded Delivery: a national survey of women's experience of maternity care. Oxford: NPEU.

Redshaw, M., Heikkila, K., 2010. Delivered with care: a national survey of women's experience of maternity care. National Perinatal Epidemiology Unit, Oxford: University of Oxford.

Ritchie, J., Spencer, L., O'Connor, W., 2003. Carrying out qualitative analysis. In: Ritchie J and Lewis J (Eds). Qualitative Research Practice: A Guide for Social Science Students and Researchers. London: Sage Publications.

Rowe, R.E., Garcia, J., Macfarlane, A.J., Davidson, L.L., 2001. Does Poor Communication Contribute to Stillbirths and Infant Deaths? A Review. Journal of Public Health Medicine 23(1), 23-34.

Sandall, J., Davies, J., Warwick, C., 2001. Evaluation of the Albany Midwifery Practice: final report. London: Florence Nightingale School of Nursing and Midwifery King's College.

Strauss, A., Corbin, J., 1990. Basics of qualitative research. Grounded theory procedures and techniques. London: Sage.

Tanassi, L.M., 2004. Compliance as strategy: the importance of personalised relations in obstetric practice. Social Science \& Medicine 59, 2053-2069.

The King's Fund, 2008. Safe Births: Everybody's business: An independent inquiry into the safety of maternity services in England. London: The King's Fund.

Williams, K., Lago, L., Lainchbury, A., Eagar, K., 2010. Mothers' views of caseload midwifery and the value of continuity of care at an Australian regional hospital. Midwifery 26, 615-621. 
Table 1: Age, parity, ethnicity and mode of birth of women interviewed

\begin{tabular}{|c|c|c|c|}
\hline & & Caseload & Standard \\
\hline Age & $\begin{array}{c}20-29 y r s \\
30-39 y r s \\
40+y r s\end{array}$ & $\begin{array}{l}6 \\
6 \\
0\end{array}$ & $\begin{array}{l}5 \\
5 \\
2\end{array}$ \\
\hline Parity & $\begin{array}{l}0 \\
1 \\
2 \\
3+\end{array}$ & $\begin{array}{l}1 \\
7 \\
4 \\
0\end{array}$ & $\begin{array}{l}3 \\
5 \\
1 \\
3\end{array}$ \\
\hline Type of birth & $\begin{array}{c}\text { SVD } \\
\text { Instrumental } \\
\text { Caesarean section } \\
\text { Twins }\end{array}$ & $\begin{array}{l}8 \\
0 \\
3 \\
1\end{array}$ & $\begin{array}{l}8 \\
2 \\
2 \\
0\end{array}$ \\
\hline Ethnicity & $\begin{array}{l}\text { White British } \\
\text { White other European } \\
\text { Black African } \\
\text { Black other } \\
\text { Indian } \\
\text { Bangladeshi } \\
\text { Oriental } \\
\text { Any other } \\
\text { Not stated }\end{array}$ & $\begin{array}{l}2 \\
2 \\
0 \\
0 \\
0 \\
2 \\
1 \\
3 \\
1\end{array}$ & $\begin{array}{l}1 \\
1 \\
3 \\
1 \\
1 \\
1 \\
0 \\
3 \\
0\end{array}$ \\
\hline
\end{tabular}


Table 2. Key themes from women's perceptions of care

\begin{tabular}{|c|c|c|}
\hline Key theme & $\begin{array}{l}\text { Women's perceptions } \\
\text { (previous study) }\end{array}$ & $\begin{array}{l}\text { Women's perceptions } \\
\text { (this study) }\end{array}$ \\
\hline $\begin{array}{l}\text { Knowing and } \\
\text { being known }\end{array}$ & $\begin{array}{l}\text { Knowing the midwife: 'my' } \\
\text { midwife; being known by the } \\
\text { midwife }\end{array}$ & $\begin{array}{l}\text { Like a friend or kin; feeling safe } \\
\text { and relaxed; being able to } \\
\text { confide; not repeating your } \\
\text { history; knowing the extended } \\
\text { family }\end{array}$ \\
\hline $\begin{array}{l}\text { Person-centred } \\
\text { care }\end{array}$ & $\begin{array}{l}\text { Care focused on me as a } \\
\text { person; someone there for you }\end{array}$ & Person-centred care \\
\hline Social support & Social support & $\begin{array}{l}\text { Support / lack of support from } \\
\text { extended family; lacking social } \\
\text { support }\end{array}$ \\
\hline $\begin{array}{l}\text { Reassurance, } \\
\text { confidence and } \\
\text { development }\end{array}$ & $\begin{array}{l}\text { Reassurance, sense of } \\
\text { confidence }\end{array}$ & Gaining trust and confidence \\
\hline $\begin{array}{l}\text { Holistic and } \\
\text { flexible care }\end{array}$ & $\begin{array}{l}\text { Flexible care, not a production } \\
\text { line; time to listen and give } \\
\text { care; place hospital to } \\
\text { community; medical and social } \\
\text { care }\end{array}$ & $\begin{array}{l}\text { Quality \& sensitivity of care: } \\
\text { time spent appropriate to needs; } \\
\text { care at home; insensitive care } \\
\text { from night staff }\end{array}$ \\
\hline $\begin{array}{l}\text { Informed choice, } \\
\text { control and } \\
\text { autonomy }\end{array}$ & $\begin{array}{l}\text { Informed choice and decision } \\
\text { making; sense of control }\end{array}$ & Communication \\
\hline
\end{tabular}

Framework source: McCourt and Stevens 2009 